\title{
Primary care in the United States: problems and possibilities
}

\author{
Robert L Phillips
}

The UK government is hoping to improve primary care through competition. But US experience shows the difficulties created by a system reliant on market forces

This article is
part of a series
examining the
government's
planned market
reforms to
healthcare
provision

Robert Graham Center, 1350

Connecticut Ave NW, Washington DC, 20036 USA Robert L Phillips assistant director

bphillips@aafp.org

BMJ 2005;331:1400-2
The United States has never had a more robust primary care workforce, but dysfunctional financing schemes and inability to compete for the hearts and minds of the next generation of young doctors threaten its future. Many of the problems are a direct result of the market approach to health care. Innovation is needed in how primary care functions are financed, protected, organised, and taught in order to identify options for a stable and robust health system built on primary care.

\section{US primary care}

Primary medical care in the US is delivered by three specialties: family medicine, general internal medicine, and general paediatrics. The specialties have a combined workforce of 222000 doctors, whose primary function is to direct patient care. There is at least one doctor for every 1321 people in the US (table). ${ }^{1}$ In addition, more than 100000 nurse practitioners and physician assistants work in primary care. ${ }^{1}$ Together, their offices serve as the medical home for most Americans and receive more visits than any other setting. ${ }^{2}$ It is concerning then that many recent publications have concluded that these specialties and the way they currently care for people is untenable. ${ }^{34}$ These publications show that people in the US are confused about the primary care specialties, sceptical about their claim to deliver comprehensive care, and unable to associate primary care with science or technology. They also indicate that the generalist specialties suffer from a lack of respect in academic circles, administrative burdens, and inflexible appointment schedules and brief visits that satisfy neither patient nor provider.

The hospitalist movement, which continues to gain a foothold in the US, is emblematic of these challenges. The hospitalist movement is based on the idea that primary care physicians should hand over the care of their patients when admitted to hospital to a team of doctors based in the hospital, rather than trying to attend them themselves. Giving up hospital care is often more financially lucrative for primary care doctors, and many hospitalists are themselves primary care doctors.

The three specialties are also having trouble attracting new doctors. ${ }^{56}$ How is it that the specialties on which most Americans rely for medical care and integration of their healthcare services, in a country that spends nearly $\$ 2$ trillion ( $\$ 6700$ ( $£ 3900$; $€ 5700$ ) per person) on health care, find themselves in an untenable position?

\section{Problems facing primary care}

Many of the issues and concerns raised in the past few years remain-namely, dissatisfaction, long hours, high

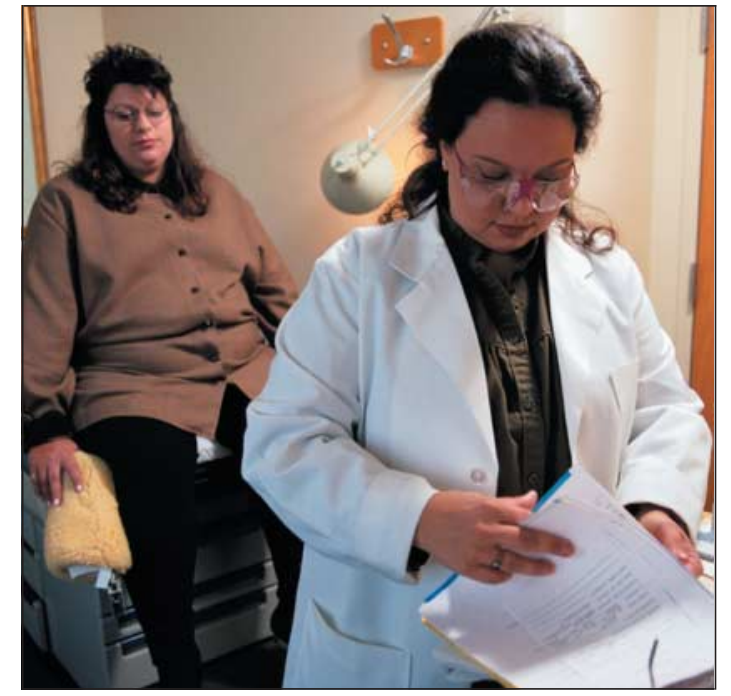

The US undervalues family doctors

stress, poor reimbursement, and erosion of scope of practice. $^{78}$ These are often just symptoms, though, of the greater overall failure in the US in deciding the purpose of the healthcare system. It currently operates as a marketplace darling, consuming nearly $16 \%$ of the overall economy and nearly $25 \%$ of its annual growth. ${ }^{9}$ Its role as a reliable economic engine produces amazing technology and pharmaceutical development, but it also yields uninsurance and underinsurance, poor population health compared with other developed countries, and unethical disparities in both health and health care.

This purpose of the US healthcare system, as a prime driver of the US economy, has reduced spending for other social programmes, such as education, and in doing so threatens health. ${ }^{9}$ Why does this matter for primary care? It matters because primary care is a platform for improving population health, not wealth. Or, as Larson and colleagues put it: "The investment capital that drives service and program development in medicine is generally not being used to develop primary or generalist medical services. Instead, as in every market economy, capital is being invested to expand the more lucrative services."11 For all the US's fiscal largesse, there is relative underinvestment in primary care.

The lower salaries of doctors in primary care compared with hospital specialists dissuade medical students, half of whom now graduate $\$ 115000$ or more in debt, from pursuing primary care careers. ${ }^{12}$ The median salary for a generalist physician in the US is currently 
Distribution of doctors in United States, 2004

\begin{tabular}{lccc} 
& Primary care & Subspecialists & Total \\
\hline No of doctors & 222059 & 398568 & 620627 \\
\hline No of people/doctor & 1321 & 736 & 472 \\
\hline $\begin{array}{c}\text { Doctors/100 000 } \\
\text { population }\end{array}$ & 75.8 & 136.0 & 211.5
\end{tabular}

*Doctors who spend most of their time directly caring for patients (American Medical Association Physician Masterfile, 2004).

about $\$ 130000$ whereas a radiologist will earn $\$ 298000 .^{13}$ Fee for service is the dominant payment scheme for primary care and promotes a piecework approach to care and increased patient volume rather than continuity, comprehensiveness, or integration of care. The services of primary care doctors have long been undervalued by the Medicare programme, which often cuts its annual payments to cope with overspending on procedures in secondary and tertiary care. ${ }^{14}$ Underinvestment and relatively low financial margins can make it difficult for primary care doctors to move to models of care that deliver higher quality. Implementing electronic health records or effective team based care requires great personal expense. ${ }^{15}$

The difficulties that primary doctors face in transforming care make it difficult for them to commit to meeting predetermined measures of quality. Despite these difficulties, primary care professional organisations are helping develop evidence based measures of quality and facilitating clinical transformation. ${ }^{16}{ }^{17}$ This leadership may provide financially feasible means for primary care to succeed and enhance the delivery of fuller primary care functions for the population.

The US Congress may yet succeed in implementing a scheme that pays doctors for performance, but it won't come with new money attached. Medicare pay for performance may in fact do more harm than good to primary care if it is expected to achieve the dual purposes of improving quality and reducing costs. ${ }^{18} 19$ There is a glimmer of hope that healthcare purchasers and insurers are waking up to the benefits of effective primary care and have some willingness to support more effective primary care. $^{20}$ In the meantime, primary care providers are beginning to bring the more lucrative technologies and ancillary services back into their offices as a means of surviving. ${ }^{21}$

\section{Costs of neglecting primary care}

Most countries that have built their healthcare systems on primary care enjoy better population health outcomes, lower health disparities, more equitable access to care, and lower costs. ${ }^{22}{ }^{23}$ There are trade-offs of course, but what should $\$ 2$ trillion purchase? If primary care cannot make the considerable investment required to transform its business and clinical model, and cannot attract new doctors, the result will be worsened health outcomes and disparities. The same outcome may result if primary care abandons its core functions and instead survives by providing expensive technology and ancillary services. Continuing to stoke the healthcare economic engine for purposes other than producing health is also unlikely to be sustainable. Things could get much worse for primary care and people in the US before they get better.

\section{Possible solutions}

\section{Pay for care differently}

The US is jealous of the NHS investment in general practice infrastructure and measures of quality. ${ }^{24} \mathrm{No}$ obvious source of such direct investment exists in the US, but blended payment models have been increasingly advocated as a potential solution. These models would blend fees for service with monthly patient management fees or other forms of capitation to support the broader array of primary care functions and help avoid the particular pitfalls of the individual types of payment. ${ }^{25-27}$ Ginsburg, president of the Center for Studying Health System Change, has written:

The mechanism of payment for primary care services can be a substantial impediment to achieving the vision of the primary care of the future. Fee-for-service payment is not evolving in the same way that the practice of medicine is. Primary care practice now involves more telephone and e-mail communication with patients and time spent on management and coordination of care. ${ }^{27}$

Without new models of payment, new models of care will struggle to evolve.

\section{Separate fund pools}

Separating funding for primary care from secondary and tertiary care could protect primary care from costs in more expensive settings and preserve access to primary care for patients. The UK has tried various means of separation, and the US could learn from these. One mechanism for this in the US would be to split the Medicare sustainable growth rate formula into evaluation and management codes (which mainly apply to primary care) and other codes (mostly procedural and used in secondary and tertiary care). This would protect the most important primary care functions from the cost cutting required when Medicare spending targets are exceeded (largely due to procedural costs). ${ }^{14}$

Separation of funding for primary and secondary care could also facilitate different ways of paying for care and the transformation of primary care. Other healthcare purchasers and payers could make similar separations in their funding pools since they tend to follow Medicare's lead in payment policies. Such a separation could also promote quality and safety by assuring access to essential and robust primary care services while reducing overuse of other treatments.

\section{Rallying primary care doctors and providers}

The work, settings, and compensation of general internists and paediatricians are more similar to those of family physicians than those of subspecialist internists or paediatricians. ${ }^{6}$ The three primary care specialties could rally around their common problems and policy options and develop teams better able to integrate personal, family, and community health needs. For example, paediatrics recently wrestled with the specialty's role in caring for families in the context of caring for children. ${ }^{28}$ The political and clinical integration of these specialties could unify more than a third of all US doctors and create a force for change.

\section{Hearts and minds}

Efforts to resolve the financial and systemic frustrations of primary care doctors would go a long way 


\section{Summary points}

Health care is an important economic driving force in the United States

Emphasis on new technology and market forces has resulted in undervaluation of primary care

US primary care lacks resources to invest in change

The US need to move away from fee for service payments to support a broad range of primary care services

Innovations in organisation and teaching are also required

towards inspiring medical students and residents. So would making residency programmes the focus of the first waves of clinical transformation. Training programmes could become laboratories for change, producing new doctors who expect to work in high performance settings. The US also needs to explore changes in residency training that offer students more flexibility and focused training opportunities within primary care. ${ }^{29}$ Currently, the generalist specialties, accrediting bodies for training programmes, and certifying boards operate semi-autonomously; however there is sufficient reason for them to consider collaborating to promote innovation. Such change may be essential to ensure the next generation of capable primary care doctors.

\section{Time for experimentation}

By some measures of sufficiency, the primary care workforce in the US has never been more capable of caring for people. Is it just in time to witness its demise, or just in time to retool and transform its clinical models and role in the healthcare system? The problems and possibilities may be coming into adequate alignment to permit a previously unthinkable period of experimentation. Such experiments could include how primary care is financed, how it may be protected from financial cannibalism by secondary and tertiary care, how it is organised, and how it is taught. Innovation and experimentation will be essential such that when, not if, the US healthcare economic engine finally overheats, tested options will be available for building a sustainable system built on primary care.

Contributors and sources: RLP has studied and reported widely on physician workforce issues both in the US and internationally. $\mathrm{He}$ is a former member of the American Medical Association Council on Medical Education and past president of the National Residency Matching Program.

Competing interests: None declared.

1 Green LA, Dodoo MS, Ruddy G, Fryer GE, Phillips RL, McCann JL, et al. The physician workforce of the United States: a family medicine perspective. Washington, DC: Robert Graham Center, 2004
2 Green LA, Fryer GE Jr, Yawn BP, Lanier D, Dovey SM. The ecology of medical care revisited. N Engl J Med 2001:344:2021-5.

3 Martin JC, Avant RF, Bowman MA, Bucholtz JR, Dickinson JR, Evans KL, et al. The future of family medicine: a collaborative project of the family medicine community. Ann Fam Med 2004;2(suppl 1):S3-32.

4 Larson EB, Grumbach K, Roberts KB. The future of generalism in medicine. Ann Intern Med 2005;142:689-90.

5 Garabaldi RA, Popkave C, Bylsma W. Career plans for trainees in internal medicine residency programs. Acad Med 2005;80:507-12

6 Schwartz MD, Basco WT Jr, Grey MR, Elmore JG, Rubenstein A. Rekindling student interest in generalist careers. Ann Intern Med 2005; $142: 715-24$

7 Bodenheimer T. Innovations in primary care in the United States. $B M J$ 2003;326:796-9

8 Bindman $\mathrm{AB}$, Majeed A. Organisation of primary care in the United States. BMJ 2003;326:631-4.

9 Sager A, Socolar D. Data brief No. 8: Health costs absorb one-quarter of economic growth, 2000-2005. Boston, MA: Boston University School of Public Health, 2005.

10 Emanuel E. Political problems. In: Daniels N, Kennedy B, Kawachi I, Cohen J, Rogers J, eds. Is inequality bad for our health? Boston: Beacon Press, 2000:59-66.

11 Larson EB, Roberts KB, Grumbach K. Primary care, generalism, public good: déjà vu? again! Ann Intern Med 2005;142:671-4.

12 Association of American Medical Colleges. Medical student education: cost debt, and resident stipend facts. Washington, DC: AAMC, 2005. www.aamc.org/students/financing/debthelp/factcard05.pdf (accessed 21 Nov 2005).

13 Medical Group Management Association. Physician compensation and productivity survey. Washington, DC:MGMA, 2004.

14 Dodoo MS, McCann JL, Phillips RL. White paper:preliminary report on the medicare sustainable growth rate: evaluation and management code analysis Washington, DC: Robert Graham Center, 2004

15 Phillips RL Jr, McCann J. Cost-effective roles for nurse practitioners in secondary prevention. BMJ 2005:330(7504):E357-8

16 Ambulatory Care Quality Alliance. Recommended starter set: clinical performance measures for ambulatory care, 2005. www.ahrq.gov/qual/ aqastart.htm (accessed 21 Nov 2005).

17 Porter S. AAFP invests millions in practice resource center. AAFP News Now 2005 Jan 1. www.aafp.org/x33119.xml (accessed 21 Nov 2005)

18 Straube B. The CMS quality roadmap: quality plus efficiency. Health Aff (Milwood) 2005 Nov 16 [epublication ahead of print].

19 Rattray MC, Andrianos J, Stam D. White paper:revisiting quality implications of efficiency-based clinician profiling. Regence Group, 2004 www.regence.com/research/docs/revisitingQualityImplications.pdf (accessed 21 Nov 2005).

20 Working Group for Financing and Incentives. Parallel pathways for qualit healthcare: a framework for aligning incentives with quality and health information technology. eHealth Initiative, 2005. www.ehealthinitiative.org/assets/ documents

eHIWorkingGrouponFinancingFinalRecommendations 052505 Final.pdf (accessed 21 Nov 2005)

21 Stover J. Health care competition may hurt primary care, poor patients AAFP News Now 2005 Oct 17. www.aafp.org/x39577.xml (accessed 21 Nov 2005).

22 Starfield B, Shi L, Macinko J. Contribution of primary care to health systems and health. Milbank $Q 2005 ; 83: 457-502$.

23 Ferrer RL, Hambridge SJ, Maly RC. The essential role of generalists in health care systems. Ann Intern Med 2005;142:691-9.

24 Leatherman S, Berwick DM. The NHS through American eyes; It has an enviable goal and constancy of purpose: build on it. BMJ 2000;321:1545-6.

25 Davis K, Schoenbaum SC, Audet A. A 2020 vision of patient-centered primary care. J Gen Intern Med 2005;20:953-7.

26 American Academy of Family Medicine. The new model of primary car Washington, DC: AAFM, 2004. www.aafp.org/PreBuilt/ caremanagementpolicy.pdf (accessed 21 Nov 2005).

27 Ginsburg PB. Payment and the future of primary care. Ann Intern Med 2003; $138: 233-4$

28 Schor EL. American Academy of Pediatrics task force on the family. Pediatrics 2003;111:1541-71.

29 Whitcomb ME, Cohen JJ. The future of primary care medicine. $N$ Engl J Med 2004:351:710-2.

\section{Endpiece}

\section{All change}

Formerly, when religion was strong and science weak, men mistook magic for medicine; now, when science is strong and religion weak, men mistake medicine for magic.

Thomas Szasz (b 1920), Hungarian born psychiatrist, in The Second Sin, 1973

Submitted by Sandeep Kumar Goyal, student, Maulana Azad Medical College, India 